\title{
Vacuum assisted closure system in the management of postoperative complex enterocutaneous fistulae: Postoperative Cohort Study
}

\author{
Amr Salem Samak ${ }^{1}$ M.Sc; Mahmoud Mohamed Abo Elyazeed ${ }^{2}$ MD; Ayman Helmy Ibrahim² MD
}

* Corresponding Author:

Amr Salem Samak

amrsamak@hotmail.com

Received for publication Febuary 5, 2020; Accepted Juve 3, 2020; Published online September 5, 2020.

Copyright 2020 The Authors published by Al-Azhar University, Faculty of Medicine, Cairo, Egypt. All rights reserved. This an open-access article distributed under the legal terms, where it is permissible to download and share the work provided it is properly cited. The work cannot be changed in any way or used commercially.

doi: $10.21608 /$ aimj.2020.23559.1134

${ }^{l}$ General Surgery Department, Mokattam Health Insurance Hospital.

${ }^{2}$ General Surgery Department, Al Hussein University Hospitals, AlAzhar University

\begin{abstract}
Background: There is controversy in the use of vacuum assisted closure therapy (VAC) in management of enterocutaneous fistula (ECF). Due to the increased risk of new fistula formation, its use was contraindicated, but then several studies reported successful closure, fistula effluent control and healing of excoriated skin by keeping it dry.

Objectives: The aim of this study is to evaluate the efficacy of VAC in treatment of the complex postoperative ECF.

Patient and Methods: Patients with postoperative ECF were enrolled in this prospective study in the period from January 2018 to June 2019. Full history, examination and investigations were done for all patients. Patients had VAC. After one month, responses to VAC in terms of time from fistula to VAC, general condition, fistula output, fistula closure, wound size, skin condition, time to start oral feeding, need to segregate, complications and mortality were recorded. On follow-up, time to complete closure, type of closure and cost were recorded. Results were then analyzed.

Results: 60 patients with ECF were enrolled. General condition was improved in 32 patients while ECF output was improved in 52 patients. Early start of Oral feeding had occurred with the use of VAC. Complications as pain, new fistula formation, pulmonary embolism or ongoing sepsis occurred in 40 patients while mortality occurred in 12 patients.

Conclusion: VAC is feasible in complex postoperative enterocutaneous fistulae. It enhances the survival, improves the general condition and the perifistular skin and reduces the fistula output and wound size.
\end{abstract}

Keywords: Vacuum Assisted Closure; Postoperative enterocutaneous fistula; Complex enterocutaneous fistula

Disclosure: The authors have no financial interest to declare in relation to the content of this article. The Article Processing Charge was paid for by the authors.

Authorship: All authors have a substantial contribution to the article.

\section{INTRODUCTION}

An enterocutaneous fistula (ECF) is defined as an abnormal connection between skin and intestine. A fistula is simple when it had a short track that communicates directly with the skin, or more complex, when it is associated with abscess formation or involvement of multiple loops of bowel with multiple openings on the skin. ${ }^{1}$

The etiology of ECF can be iatrogenic in $(75-85 \%)$ or spontaneous in $(15-25 \%)$. Iatrogenic causes trauma, operations for malignancy associated with extensive adhesiolysis...etc. Spontaneous fistulae occur from IBD, malignancy, radiation ....etc. ${ }^{2}$
There is controversy in the use of vacuum assisted closure (VAC) system in management of ECF. It had been contraindicated as it increases the risk of new fistula formation, but as time went by, VAC therapy revealed itself to be a "Swiss knife multi-tool"; a single device with multiple functions in ECF. ${ }^{3}$

Several studies of VAC reported successful closure of ECF but the main advantages of VAC were decreasing fistula effluent and enhancing healing of excoriated skin by keeping skin dry. ${ }^{4}$

The aim of the study is the evaluation of the efficacy of the VAC therapy in treatment of the complex postoperative enterocutaneous fistula. 


\section{PATIENT AND MATERIALS}

This prospective present study was carried out at AlHussein University hospital and Al-Mokattam Health insurance hospital in the period from January 2018 to June 2019.

The patients enrolled in this study were those who had postoperative complex enterocutaneous fistulae, non-surgical candidates due to bad general conditions with no chronic debilitating diseases, age ranging from 20-60 years in both sexes and no evidence for the presence of distal obstruction, malignancy, IBD, diverticulitis, foreign body or visible intestinal mucosa while patients with postoperative simple fistula, pancreatic- or biliary atmospheric fistula, spontaneous fistulae or fistulae with exposed organs, intestinal loops or blood vessels, patients that had initial surgery for fistula repair, impaired renal function, hepatic function or hypoalbumenimia or patients on steroids, chemotherapy or radiotherapy were excluded from the study

After counseling, consenting and approval of ethical committee, all patients were subjected to complete history taking, full general and local examination and full laboratory and imaging investigations to identify origin, length and course of fistula, the presence of multiple openings or intervening abscess cavity:

After proper resuscitation, all patients had VAC therapy by the use of the VAC device manufactured by (KCI, San Antonio, TX) for their enterocutaneous fistulae with regular dressing changes Figure (1).

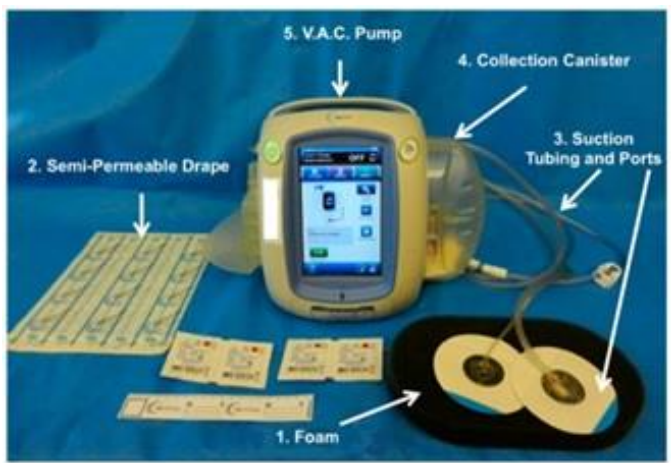

Figure 1: Components of VAC system ${ }^{5}$

A drainage tube was located on top of the foam then a second piece of foam was placed on top of it or a Sensa TRAC pad was applied over a hole in the drape opposite to the fistula.

The foam, the first few inches of the drainage tube and the surrounding area of healthy skin were covered with an adhesive membrane to form a good seal. The drain was then connected to the VAC.

Once it is switched on, the air is sucked out causing drawing the edges of the wound in. Fluid was taken out and transported to the disposable container.

VAC pressure was adjusted to $125 \mathrm{mmHg}$ negative pressure with a cycle of $5 \mathrm{~min}$ suction and $2 \mathrm{~min}$ off suction. Higher negative pressure up to $200 \mathrm{mmHg}$ was used in high output fistula to prevent leakage below the drape and detachment of the dressing and thus decompression of the VAC system. The dressing was changed at 48 hour intervals initially then the period was adjusted Figure (2).
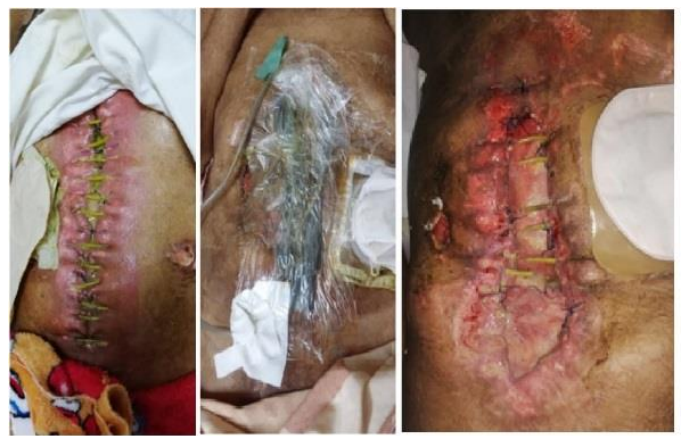

Figure 2: Male patient with intestinal fistula at the level of the umbilicus originated from the jejunum after leakage from an eneterotomy that was made to extract a solid object that caused intestinal obstruction after its ingestion. VAC was applied after 3 days from the onset and the fistula took 18 days to close. The patient then sought plastic surgery for wound closure.

After one month, response to VAC therapy in terms of time from fistula VAC, general condition, the reduction in fistula output, the occurrence of fistula closure, the wound size, the skin condition, time to start oral feeding and the occurrence of complications or mortality was recorded. On followup, time to complete closure and type of closure either spontaneously or surgically were recorded. The cost of treatment was then recorded.

Data were collected and entered to the computer using SPSS (Statistical Package for Social Science) program version 26.0, SPSS Inc., Chicago, Illinois, USA for statistical analysis. Descriptive statistics was expressed as mean, SD and range in quantitative data and as frequency and percentage in qualitative analysis. Analytical statistics for qualitative data was done by using Chi-square test while Student t-test was used for quantitative data, Kaplan-Meier survival analysis and multiple logistic regression analysis for multivariate analysis. $\mathrm{P}$ (probability) value less than 0.05 was considered statistically significant.

\section{RESULTS}

Sixty patients had VAC for ECF. After the use of VAC, mortality occurred in 12 patients. 8 patients died of ongoing sepsis despite of VAC and 4 patients died from pulmonary embolism (Figure 3). According to mortality, patients were classified into two groups; survival group that consisted of 48 patients and mortality group that consisted of 12 patients. 


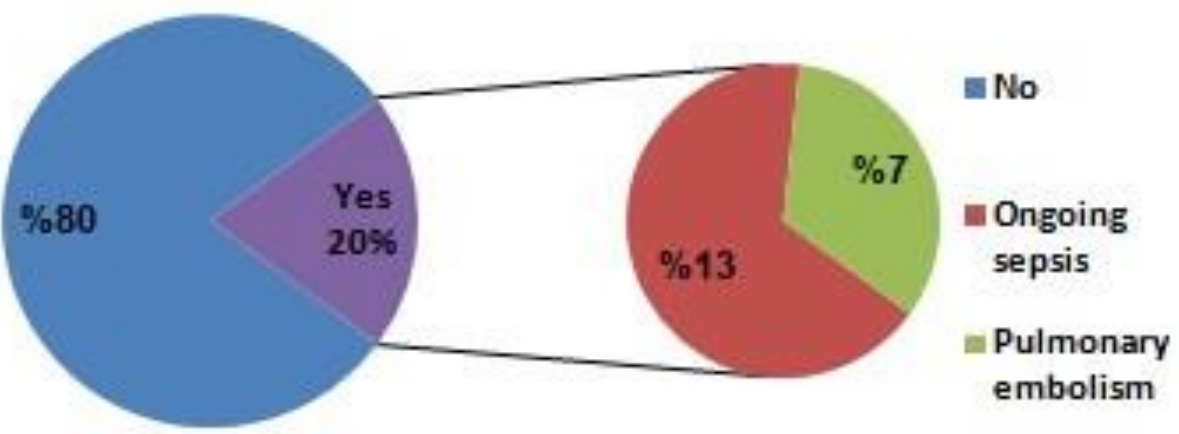

Figure 3: Mortality after VAC therapy

In this study, 44 patients were male and 16 patients were female with age range 27-65 years. Smoking was found in 20 patients. Surgical history was found in 42 patients while family history of IBD was found in 4 patients. The presence of past surgical history and BMI were statistically different ( $p<0.001,0.038$ respectively). It was found that the amount of hemoglobin,platelets and the level of serum sodium and calcium was significantly higher in the survival group ( $\mathrm{p}$ 0.001, <0.001, 0.033 and <0.001 respectively). Levels of serum urea and creatinine were significantly lower in the survival group ( $p$ $0.018,0.006$ respectively). Mortality in patients that had ECF during emergency operations was significantly higher than elective group (p 0.012). The fistula was gastric and duodenal in the mortality group $(\mathrm{p}<0.001)$ while all fistulae in this group were deep $(>2 \mathrm{~cm})(\mathrm{p}<0.001)$. The time that elapsed from the onset of fistula to VAC were different $(\mathrm{p}<0.001)$ Table (1).

Regarding the clinical outcome, no difference in terms of the time to start oral feeding but the improvements in general and perifistular skin condition, the reduction in fistula output and wound size, the need to segregate and the occurrence of complications were all significantly better in the survival group ( $\mathrm{p}<0.001,<0.001,<0.001,<0.001$, 0.023, 0.006 respectively) Figure (4).

\begin{tabular}{|c|c|c|c|}
\hline Data & Survival Group $(\mathrm{N}=48)$ & $\begin{array}{l}\text { Mortality Group } \\
(\mathrm{N}=12)\end{array}$ & $\mathrm{p}$ value \\
\hline Age (Years) & $48.5 \pm 13.24$ & $45.67 \pm 14.51$ & $0.547 \triangle$ \\
\hline Male Sex & $36(75 \%)$ & $8(66.67 \%)$ & $0.559^{\wedge}$ \\
\hline Smoking & $16(33.33 \%)$ & $4(33.33 \%)$ & $1^{\wedge}$ \\
\hline Past Medical History & $40(83.33 \%)$ & $8(66.67 \%)$ & $0.197^{\wedge}$ \\
\hline Past Surgical History & $20(41.67 \%)$ & $12(100 \%)$ & $<0.001^{\wedge} *$ \\
\hline Past Family History (IBD) & $4(8.33 \%)$ & $0(0 \%)$ & $0.301^{\wedge}$ \\
\hline $\mathrm{BMI}\left(\mathrm{kg} / \mathrm{m}^{2}\right)$ & $24.75 \pm 9.9$ & $32 \pm 11.79$ & $0.038 \triangle *$ \\
\hline Hemoglobin $(\mathrm{g} / \mathrm{dl})$ & $8.31 \pm 1.09$ & $7.52 \pm 0.517$ & $0.001 \Delta^{*}$ \\
\hline Platelets $\left(\times 10^{9} / \mathrm{L}\right)$ & $158.6 \pm 45.4$ & $124.67 \pm 8.71$ & $<0.001 \triangle^{*}$ \\
\hline Urea (mg/dl) & $33.49 \pm 5.74$ & $43.62 \pm 26.5$ & $0.018 \Delta^{*}$ \\
\hline Creatinine $(\mathrm{mg} / \mathrm{dl})$ & $3.36 \pm 0.891$ & $5.02 \pm 1.69$ & $0.006 \triangle *$ \\
\hline Sodium (mEq/L) & $132.11 \pm 8.15$ & $126.23 \pm 4.39$ & $0.033 \Delta^{*}$ \\
\hline Calcium (mg/dl) & $8.77 \pm 0.802$ & $7.53 \pm 0.372$ & $<0.001 \triangle^{*}$ \\
\hline Emergency operation & $25(52.08 \%)$ & $11(91.67 \%)$ & $0.012^{\wedge} *$ \\
\hline \multicolumn{4}{|l|}{ Fistula Origin } \\
\hline Stomach & $8(16.67 \%)$ & $4(33.33 \%)$ & \multirow[t]{4}{*}{$<0.001^{\wedge *}$} \\
\hline Duodenum & $8(16.67 \%)$ & $8(66.67 \%)$ & \\
\hline Jejunum & $20(41.67 \%)$ & $0(0 \%)$ & \\
\hline Ileum & $12(25 \%)$ & $0(0 \%)$ & \\
\hline Deep fistula $(>2 \mathrm{~cm})$ & $20(41.67 \%)$ & $12(100 \%)$ & $<0.001 \wedge *$ \\
\hline $\begin{array}{l}\text { Time from fistula to VAC } \\
\text { (Days) }\end{array}$ & $16.58 \pm 10$ & $27.67 \pm 3.45$ & $<0.001 \triangle^{*}$ \\
\hline
\end{tabular}

Table 1: Demographic and postoperative data 


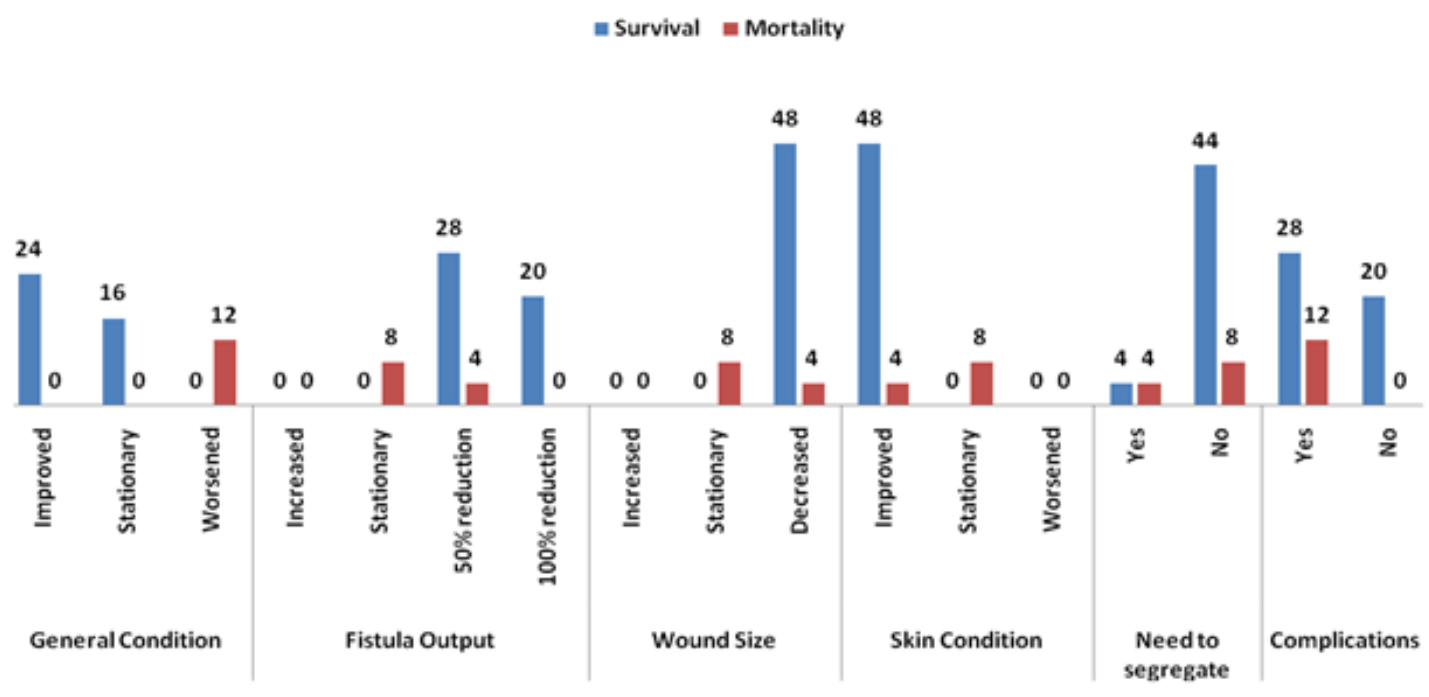

Figure 4: Response to VAC in both groups

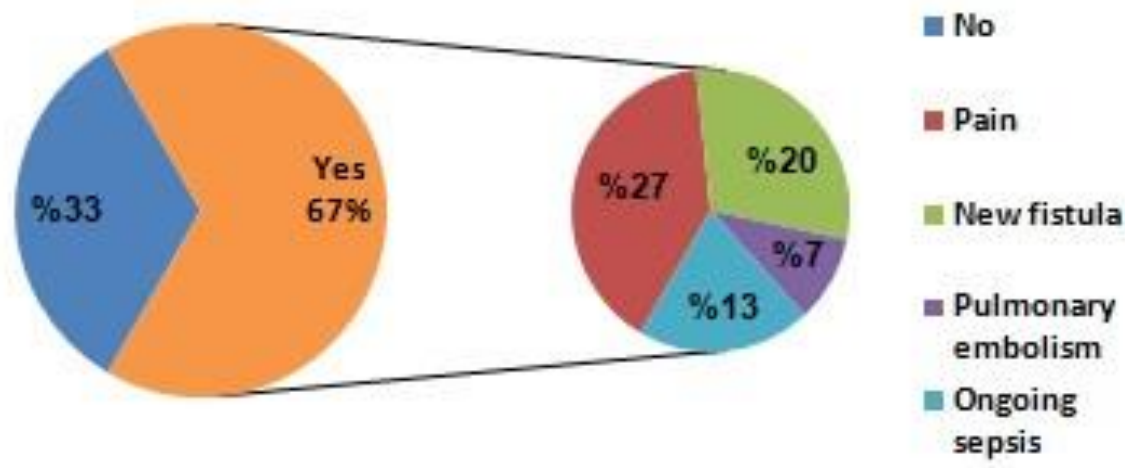

Figure 5: Complications after VAC therapy

40 patients $(66.67 \%)$ had complications. They varied from pain in 16 patients, new fistula formation in 12 patients, development of pulmonary embolism in 4 patients and ongoing sepsis in 8 patients Figure (5).

The survival probability in this study was $83.6 \%$ after 30 days and 59.8\% after 42 days Figure (6).
By multivariate analysis, the most important variable that affect the mortality was the amount of calcium (OR 61.46) followed by past surgical history (OR 36.22 ) and time from fistula to VAC (OR 10.99) (Table 2)

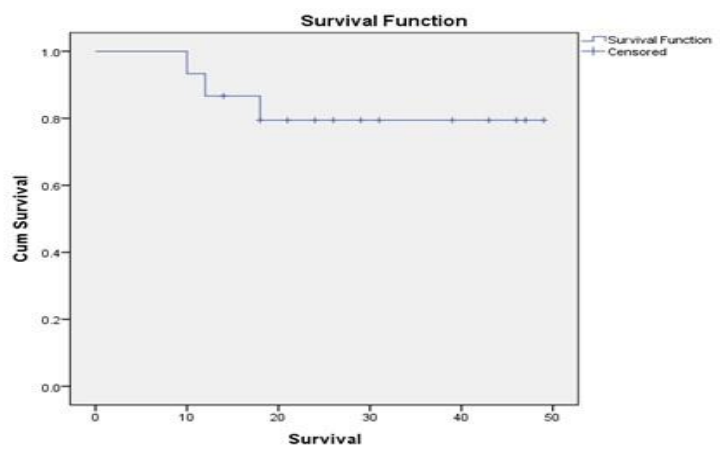

Figure 6: Kaplan-Meier Survival analysis 


\begin{tabular}{|c|c|c|}
\hline Variables & p value & Odds ratio $(\mathrm{OR})$ \\
\hline Calcium $(\mathrm{mg} / \mathrm{dl})$ & $<0.001$ & 61.46 \\
\hline Surgical History & $<0.001$ & 36.22 \\
\hline Time from onset of fistula to VAC (Days) & $<0.001$ & 10.99 \\
\hline Fistula Length & $<0.001$ & 8.99 \\
\hline Creatinine $(\mathrm{mg} / \mathrm{dl})$ & 0.006 & 4.39 \\
\hline Hemoglobin $(\mathrm{g} / \mathrm{dl})$ & 0.001 & 1.56 \\
\hline Sodium $(\mathrm{mEq} / \mathrm{L})$ & 0.033 & 1.42 \\
\hline BMI $(\mathrm{kg} / \mathrm{m} 2)$ & 0.038 & 1.08 \\
\hline Type of operation & 0.012 & 1.37 \\
\hline Fistula Origin & $<0.001$ & 0.08 \\
\hline Urea $(\mathrm{mg} / \mathrm{dl})$ & 0.018 & 1.05 \\
\hline Platelets $\left(\times 10^{9} / \mathrm{L}\right)$ & $<0.001$ & 1.31 \\
\hline
\end{tabular}

Table 2: Multivariate analysis

Regarding survived patients, spontaneous closure occurred in 32 patients while surgical intervention to close the fistula by resection/anastomosis of the bowel or plastic intervention to close the defect were required in 16 patients to accomplish complete closure. The mean time to complete closure was $32.25 \pm 12.17$ days while the mean cost of treatment in all included patients was $7540 \pm 1001.46$ Egyptian pounds Table (3).

\begin{tabular}{|l|c|}
\multicolumn{1}{|c|}{ Outcome } & \multicolumn{1}{c|}{$\begin{array}{c}\text { No. of Patients } \\
(\mathbf{N = 4 8})\end{array}$} \\
\hline Spontaneous closure & $32(66.67 \%)$ \\
\hline $\begin{array}{l}\text { Time to complete closure } \\
\text { (Days) }\end{array}$ & $32.25 \pm 12.17(14-49)$ \\
\hline $\begin{array}{l}\text { Cost of treatment } \\
\text { (Egyptian Pounds) }\end{array}$ & $7540 \pm 1001.46(5200-$ \\
\hline
\end{tabular}

Table 3: Outcome of VAC in survived patients

\section{DISCUSSION}

The VAC is a type of NPWT that is not specifically approved for ECF, with increasing application but currently controversial utility for ECF. It is not possible to determine from these two studies whether there was a cause-effect relationship between NPWT and fistula closure/output reduction. Multiple small case reports exist to document benefit of VAC therapy. ${ }^{2}$ So, we aimed to study the feasibility of VAC in ECF closure and control.
The mean of age in this study was $47.93 \pm$ 13.78 years while it was 60 years in Ortiz and colleagues (2017) study. ${ }^{6}$ The difference can be explained by the restricted inclusion criteria in our study to postoperative fistula patients against the wider inclusion criteria in the other study. 44 patients $(73.33 \%)$ had male sex. Regarding the demographic data, only the BMI and the presence of surgical history appeared to affect the survival.

BMI and the presence of past surgical history were higher in the mortality group (p 0.038, < 0.001). This can be attributed to the increased risk of injury due to difficult 
operation in obese patients and the presence of adhesions in patients with past surgical history. ${ }^{7}$

On admission, all patients in our study had anemia while $51 \%$ had anemia in Kumar and colleagues study. ${ }^{8}$ This could be contributed to the presence of increased number of patients with high output fistula in our study and the presence of low output fistula patients in the other study. Also, the platelets were higher in survival group ( $\mathrm{p}$ 0.04). In Redden and colleagues study, they found no differences in regards to platelet count between the good-outcome group and the poor-outcome group. ${ }^{9}$

In the study, the level of serum urea and creatinine affected the survival ( $p 0.006$ and 0.018 respectively). In Redden and colleagues study, they found no significant difference. ${ }^{9}$

Hyponatremia was found in $80 \%$ of patients while $60 \%$ had hyponatremia in Kumar study. ${ }^{8}$ Hypokalemic was found in all our patients but it had no effect on the survival. No evidence in the literature mentioned any relation between hypokalemia and mortality in ECF patients. Hypomagnesemia was found in $40 \%$ while hypophosphatemia was found in $73.33 \%$ with no effect on survival.

Hypocalcemia was found in $46.67 \%$. It was higher in survival group ( $\mathrm{p}$ $<0.001$ ). On multivariate analysis, the mean amount of serum calcium was the most important cause of mortality among ECF patients (OR 61.46).

Fistulae after emergency operations occurred in $60 \%$. It affected the survival ( $p$ 0.012 ) as emergency operations often performed in unfavorable conditions as hypotension, hypothermia, anemia and poor tissue oxygen delivery. So, it increases the risk of fistula formation and thus mortality. ${ }^{10}$

Wercka et al. stated that urgent surgery is a risk factor related to preoperative preparation, since the time for them tends to be shorter. There is thus an increased risk of complications. ${ }^{11}$ In the study, the higher the origin of the fistula, the higher the mortality was $(p<0.001)$. Bala et al. concluded that the anatomical location is important for worse prognosis. ${ }^{12}$

The time from fistula to VAC was found to be significantly longer in mortality group (p <0.001). It had important impact on mortality in ECF patients (OR 10.99). In the literature, all the studies, discussed the use of VAC once the fistula was diagnosed. In our study and due to several circumstances (logistics and resources), the earlier the VAC was applied, the better prognosis was found.

On follow-up, all parameters were significantly improved in the survival group. In the study of Banasiewicz and colleagues, all parameters also improved with the use of VAC. ${ }^{13}$

By VAC, peri-fistula skin had improved in 86.67\%. ( $p<0.001$ ). Segregation to draw up the fistulous opening was needed in 13.33\%. Complications occurred in $66.67 \%$. In Misky and colleague study, complications occurred in one study where abdominal wall disruption was identified in a minority of patients. ${ }^{14}$

Mortality occurred in $13.67 \%$ due to ongoing sepsis despite of VAC and $6.67 \%$ due to pulmonary embolism. The survival probability in this study was $83.6 \%$ after 30 days and $59.8 \%$ after 42 days. In Jensen et al. study, the 90-day survival was $15 \%$ without VAC. ${ }^{15}$

Regarding wound healing among the survived patients, spontaneous complete closure occurred in $66.67 \%$. The mean time to complete closure of fistula was $32.25 \pm$ 12.17 days while the mean cost of treatment in all included patients was 7540 \pm 1001.46 Egyptian pounds. In Wainstein and colleague study, output was entirely suppressed in $40.7 \%$ after 1-7 days of treatment and reduced to less than 500 $\mathrm{ml} /$ day in $57.1 \%$. Spontaneous closure was achieved in $46.2 \%{ }^{1}$

\section{CONCLUSION}

VAC use shows improved survival in patients with complex postoperative enterocutaneous fistulae, improved general condition and perifistular skin and a reduction in fistula output and wound size. The presence of hypocalcemia and past surgical history 
affect the survival. The earlier the VAC was applied, the better the prognosis was.

\section{References}

1. Orangio G. Enterocutaneous Fistula: Medical and Surgical Management including patients with Crohn's Disease. Clin Colon Rectal Surg., 2010; 23(3):142-148.

2. Gribovskaja-Rupp I and Melton G. Enterocutaneous Fistula: Proven Strategies and Updates. Clin Colon Rectal Surg., 2016; 29(2):130-7.

3. Magalini S, Pepe G, Cozza V et al. Negative pressure wound therapy (NPWT) in duodenal breakdown fistulas: negative pressure fistula therapy (NPFT)? Eur Rev Med Pharmacol Sci, 2017: 21:2452-7.

4. Tavusbay C, Genc H, Cin N, et al. Use of a vacuum-assisted closure system for the management of enteroatmospheric fistulae. Surg Today, 2015; 45(9):1102-11.

5. Mellott A, Zamierowski D and Andrews B. Negative Pressure Wound Therapy in Maxillofacial Applications. Dent J (Basel), 2016; 4(3):30.

6. Ortiz L, Zhang B, McCarthy M et al. "Treatment of Enterocutaneous Fistulas, Then and Now." Nutr Clin Pract, 2017: 32(4):508-15.

7. Hollington P, Mawdsley J, Lim W, et al. An 11year experience of enterocutaneous fistula. British Journal of Surgery, 2004; 91:1646-51.

8. Kumar P, Maroju N and Kate V. Enterocutaneous fistulae: etiology, treatment, and outcome - a study from South India. Saudi J Gastroenterol., 2011; 17(6):391-5.
9. Redden M., Ramsay P, Humphries T, et al. The Etiology of Enterocutaneous Fistula Predicts Outcome. Ochsner J., 2013; 13(4): 507-11.

10. Haack C, Galloway J and Srinivasan J. Enterocutaneous Fistulas: A Look at Causes and Management. J. Curr Surg Rep., 2014; 2:71-73.

11. Wercka J, Cagol P, Melo A, et al. Epidemiology and outcome of patients with postoperative abdominal fistula. Revista do Colégio Brasileiro de Cirurgiões, 2016; 43(2):117-23.

12. Bala M, Gazalla S, Faroja $M$, et al. Complications of high grade liver injuries: management and outcome with focus on bile leaks. Scand J Trauma Resusc Emerg Med., 2012; 20:20-23.

13. Banasiewicz T, Borejsza-Wysocki M, Meissner $\mathrm{W}$, et al. Vacuum-assisted closure therapy in patients with large postoperative wounds complicated by multiple fistulas. Wideochir Inne Tech Maloinwazyjne, 2011; 6(3):155-63.

14. Misky A, Hotouras A, Ribas Y, et al. A systematic literature review on the use of vacuum assisted closure for enterocutaneous fistula. Colorectal Dis., 2016; 18(9):846-51.

15. Jensen R, Buchbjerg $\mathrm{T}$, Simonsen $\mathrm{R}$, et al. Vacuum-Assisted Abdominal Closure Is Safe and Effective: A Cohort Study in 74 Consecutive Patients. Surgery Research and Practice, 2017; ID7845963: 5

16. Wainstein D, Tüngler V, Ravazzola $C$, et al. Management of external small bowel fistulae: Challenges and controversies confronting the general surgeon. International Journal of Surgery, 2011; 9(3):198-203. 